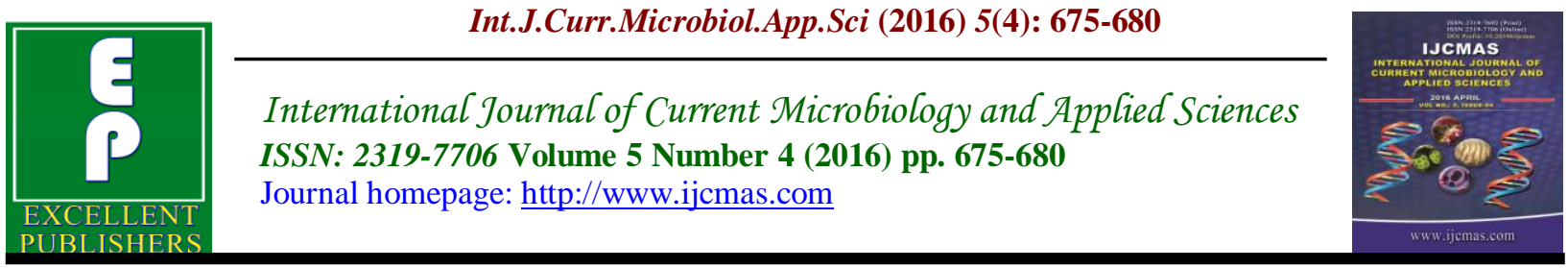

Case Study

http://dx.doi.org/10.20546/ijcmas.2016.504.077

\title{
A Report of Three Cases of Diphtheria in a Tertiary Care Hospital
}

\author{
Koripella Rama Lakshmi*, C.Siva Kalyani, Perala Balamurali Krishna, \\ N.Lakshmi, P.Anusha and Sulakshana Sony Cheemala
}

Department of Microbiology, Andhra Medical College, Visakhapatnam, Andhra Pradesh, India

*Corresponding author

\begin{tabular}{|c|c|}
\hline & A B S T R A C T \\
\hline Keywords & \multirow{3}{*}{$\begin{array}{l}\text { Most of the vaccine preventable diseases have shown a decline with the } \\
\text { advent of UIP (Universal Immunisation Programme) but Diphtheria is still } \\
\text { endemic in our country. Persistence or resurgence of Diphtheria in the } \\
\text { country is mainly due to low coverage of primary immunization as well as } \\
\text { booster doses. We report three cases of Diphtheria in children who attended } \\
\text { paediatric care unit in a tertiary care hospital. }\end{array}$} \\
\hline $\begin{array}{l}\text { Corynebacterium } \\
\text { Diphtheriae, } \\
\text { Metachromatic } \\
\text { Granules, } \\
\text { Immunisation. } \\
\text { Article Info }\end{array}$ & \\
\hline $\begin{array}{l}\text { Accepted: } \\
\text { 22 March } 2016 \\
\text { Available Online: } \\
10 \text { April } 2016\end{array}$ & \\
\hline
\end{tabular}

\section{Introduction}

There is a progressive decline in the incidence of Diphtheria with the advent of EPI (Extended Programme of Immunisation) in 1978 and UIP in 1985 until the year 2006. Then it reached a plateau and remained at 4000-5000 cases per year globally till 2012 (Patel et al., 2004; Khan). The reported incidence of Diphtheria in India during 1980 was about 39,231. It is reduced to 3094 cases in 2000 and increased to 5725 cases in 2005 (WHO, 2006) and then 3812, 3977, 3529, 3123 and 3485 cases from 2007 to 2011 (Mahantesh et al., 2014).

The recent report of National Health Profiles released by the Govt of India (Central Bureau of Health Intelligence 2013) showed that the number of reported cases of Diphtheria in Andhra Pradesh were 121 with 4 deaths (57 males with 3 deaths and 64 females with 1 death) (Central Bureau of Health Intelligence, 2013).

\section{Case I}

An 8 year old female child was brought to the Intensive Paediatric care unit, King George Hospital, Visakhapatnam with complaints of fever, cold, cough and sore throat for one day duration in the month of February 2015. There was a history of similar complaints in elder brother of the patient who was 9 years of age and he died suddenly with cough, cold, fever and respiratory difficulty 10 days prior to the 
admission of this child. On oral examination exudative follicular tonsillitis with hypertrophy with a greyish white patch and pharyngeal congestion (Figure 1) was present. Cervical lymph nodes were enlarged. The child was vaccinated but booster doses were not received as per UIP. A provisional diagnosis of Diphtheria or H1N1 was made. In addition to routine general investigations Nasopharyngeal swab in VTM (viral Transport Media) and throat swabs for Gram's stain, Albert's stain, culture \& sensitivity were sent to the Department of Microbiology.

\section{Case II}

A male child of age 3 years was admitted in IPCU (Intensive Paediatric Care Unit) one week after the first case with complaints of high grade fever with chills \& rigors, throat swelling \& pain since 7 days. There was no history of cold and cough. On oral examination greyish white patch on tonsils and pharyngeal congestion was present, cervical lymphadenopathy with swelling of neck (Bull's neck) (Figure 2)(Figure 3)was present. The child received primary immunisation as per UIP (Universal Immunisation Programme) and one booster dose. A provisional diagnosis of acute pharyngitis was made. In addition to routine general investigations, throat swab for Gram's stain, Albert's stain, culture \& sensitivity was sent to the Department of Microbiology.

\section{Case III}

A male child of age 8 years was brought to the paediatric OPD 10 days after the $2^{\text {nd }}$ case with complaints of fever, cold, cough and throat pain since 3 days. On oral examination exudative follicular tonsillitis, hypertrophy of tonsils and pharyngeal congestion were present. Cervical lymphadenopathy was present and the history of receiving of booster doses was improper. A provisional diagnosis of Diphtheria was made. In addition to routine general investigations throat swab for Gram's stain, Albert's stain, culture \& sensitivity was sent to the Department of Microbiology.

In all the three cases examination of the throat swab revealed characteristic bacilli with metachromatic granules in cuneiform arrangement on Albert's stain(Figure 4) and club shaped / dumbbell shaped, pleomorphic Gram positive bacilli on Gram's stain (Figure 5). Growth on potassium tellurite agar (Figure 6) showed black colonies \& on Loefflers serum slope (Figure 7) the colonies were small, circular white opaque, enlarged with a distinct yellow tint on continued incubation.

Based on cultural characteristics \& biochemical reactions the isolate was suspected as Corynebacterium diphtheriae biotype mitis. The $\mathrm{H} 1 \mathrm{~N} 1$ report was negative for the first case as there was suspicion of H1N1.

\section{Results and Discussion}

Diphtheria which was common among less than five years age children in the past, is now affecting older children (5-19 years) and adults (Havaldar, 1992). The majority of the cases are reported from children who were non-immunised or partially immunised against diphtheria. Persistence or resurgence of Diphtheria in the country was mainly due to low coverage of primary immunization as well as the booster doses. According to the WHO -UNICEF estimates (WHO, 2010), the DPT3 coverage was $66 \%$ in 2008 , where as, according to the three National Family Health Surveys (National Family Health Survey (MCH and Family planning India, 1995; National Family Health Survey (NFHS-3), 2005-06), DPT3 coverage during 1992-2006 was only 52-55\%. Immunity 
acquired through primary immunization wanes in early childhood. Hence adequate coverage of booster doses is equally important (Manoj et al., 2011).

Figure.1 Oral Examination Showing Exudative Follicular Tonsillitis with Hypertrophy with a Greyish White Patch and Pharyngeal Congestion

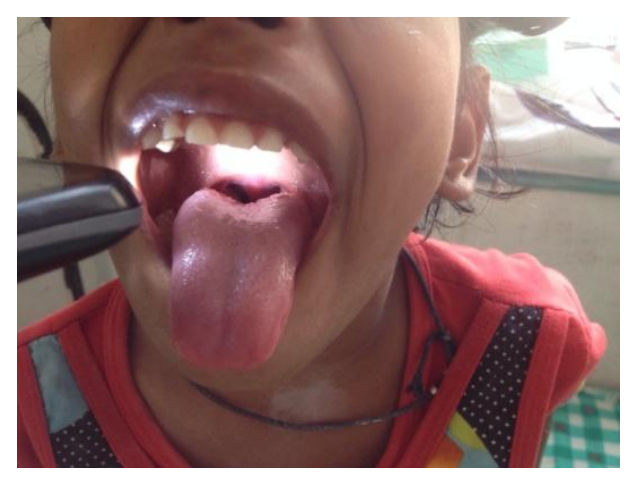

Figure.2 Cervical Lymphadenopathy

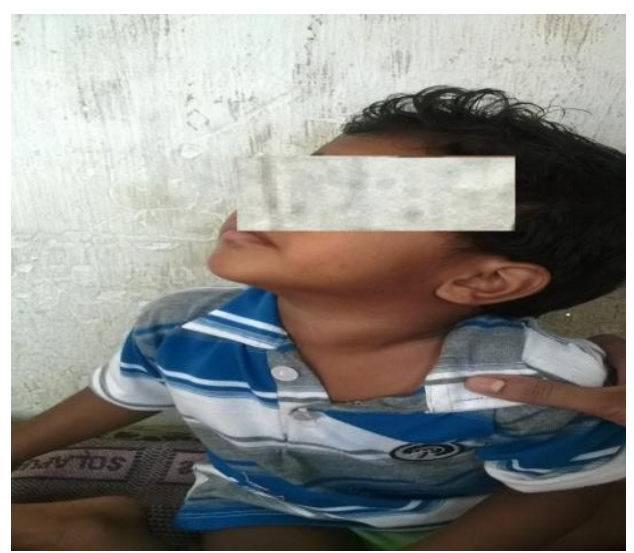

Figure.3 Swelling of Neck (Bull's neck)

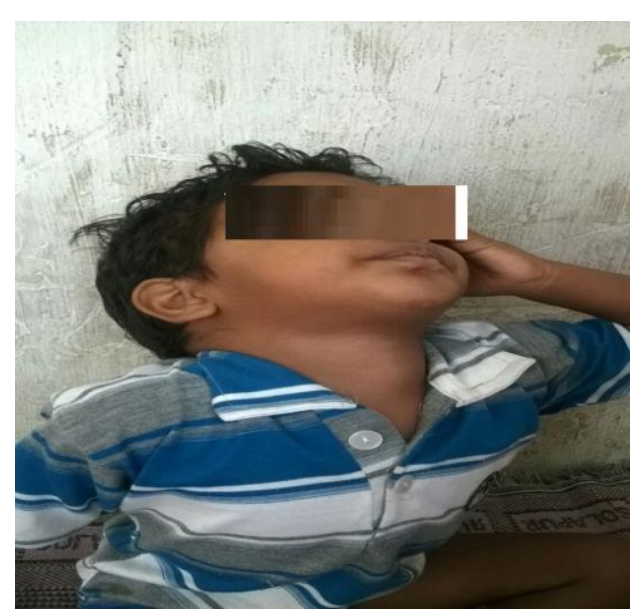


Figure.4 Albert's Stain Showing Green Bacilli with Purple Coloured Metachromatic Granules

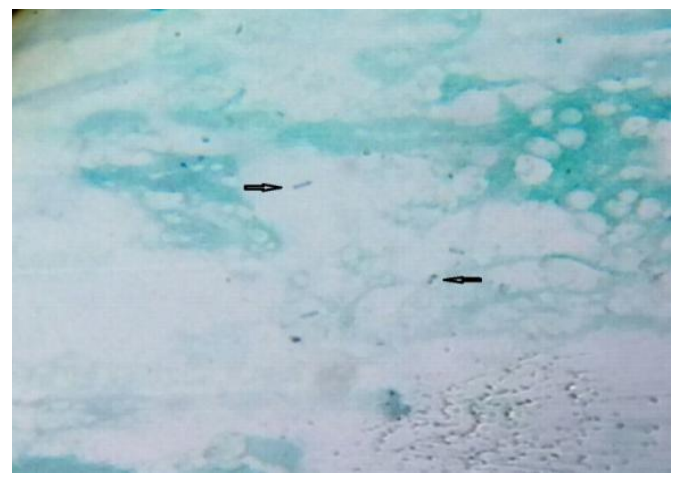

Figure.5 Gram's Stain Showing Dumbbell Shaped Gram Positive Bacilli

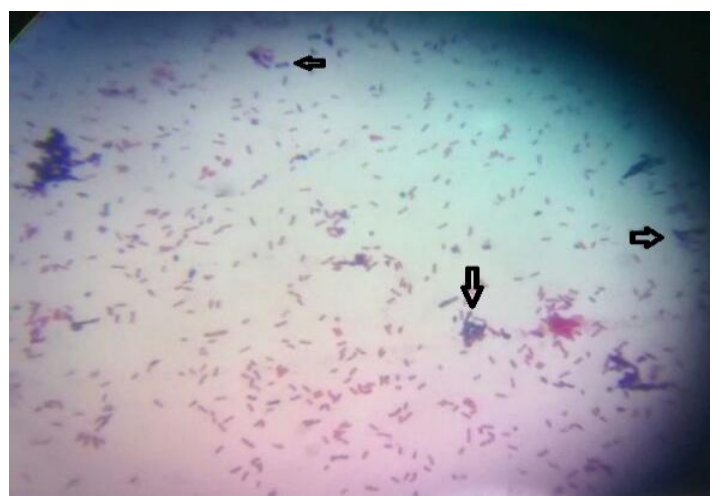

Figure.6 Potassium Tellurite Agar Showing Black Colonies

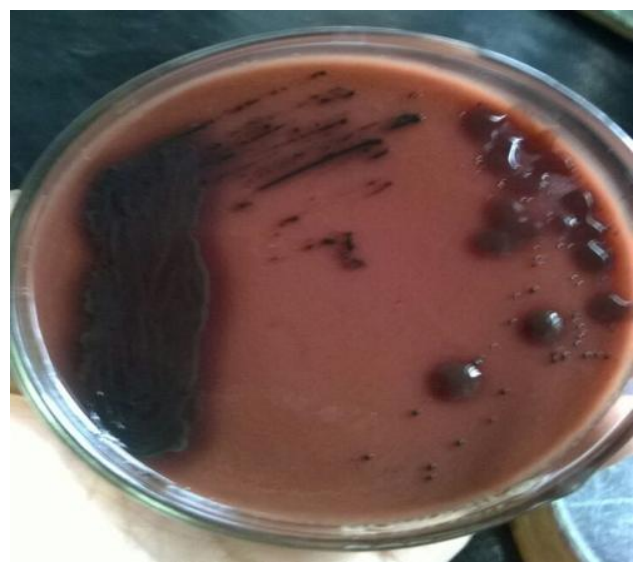


Figure.7 Loefflers Serum Slope Showing Circular White Opaque Colonies with Yellow Tint

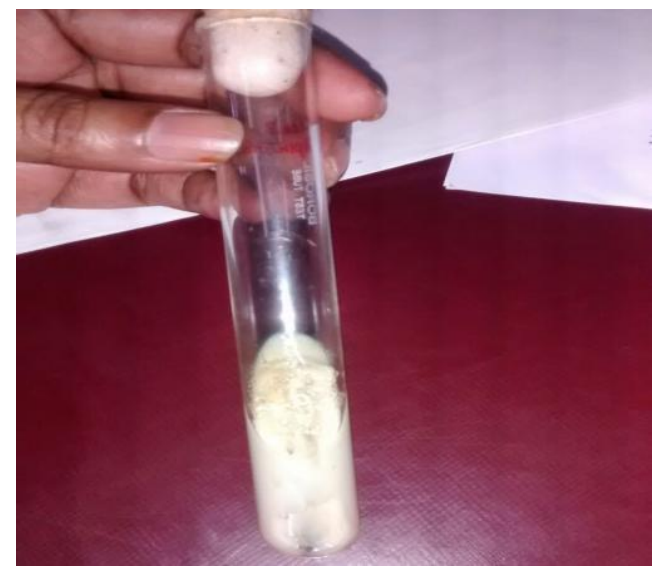

Figure.8 Antibiotic Sensitivity Testing by Disc Diffusion Method

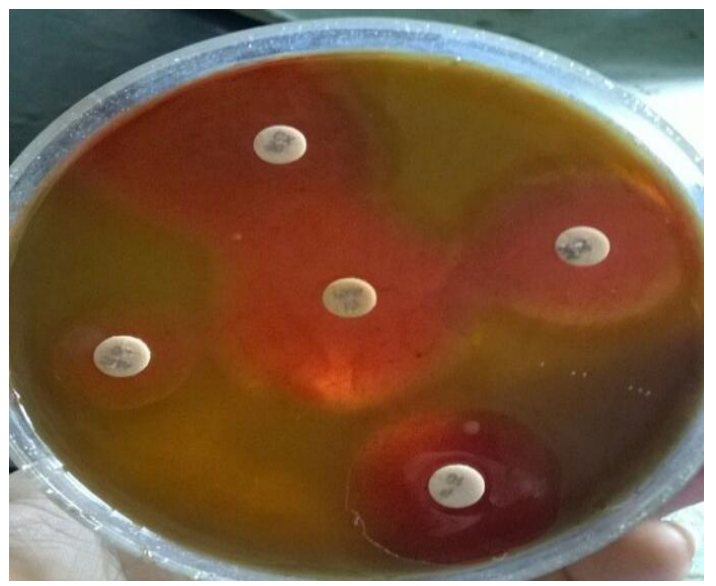

In our study all the three cases were from the nearby areas. The history of booster doses of vaccination was improper in 2 children more than 5 years of age and another child was $3 y$ rs old who received only primary immunization and one booster dose. All the three cases were recovered on administration of macrolide group of antibiotics (Figure 8) \& supportive therapy in IPCU(Intensive paediatric Care Unit). Achieving and maintaining high level of immunity especially among infants and children by high coverage of primary \& booster immunization against Diphtheria and maintenance of cold chain is necessary to reverse the trend of disease in India.

\section{References}

Havaldar, P.V. 1992. Diphtheria in the eighties: Experience in a South Indian District Hospital. J. Indian Med. Associ., 90: 15-56.

Khan, N., Shastri, J.U., Aigal, B. Doctor: Resurgence of Diphtheria in the Vaccination era.

Mahantesh, V., Parade, Aisha, M., Parade, et al. 2014. Diphthria outbreak in North Karnataka, India, JMM case reports. Central Bureau of Health Intelligence, 2013.

Manoj, V., Murhekar, Sailaja Bitragunta. 2011. Persistence of Diphthria in 
India, Indian J. Community Med., 36(2): 164-165.

National Family Health Survey (MCH and Family planning), India 1992-93. Bombay 11PS; 1995. Int. Institute for Population Sci.

National Family Health Survey (NFHS-3), 2005-06. India. Mumbai: 11PS:2007. International Institute for Population Sciences (11PS) and Macro International.
Patel, U.V., Patel, B.H., Bhavsar, B.S., Dabhi, H.M., Doshi, S.K. 2004. A retrospective study of Diptheria cases, Rajkot, Gujarat. Indian J. Community Med., 24: 16-13.

WHO. 2006. Immunization surveillance, assessment and monitoring. Immunization profile-India.

World Health Organisation. 2010. Immunisation, surveillance, assessment and monitoring. (Last Accessed on 2010 oct 07).

\section{How to cite this article:}

Koripella Rama Lakshmi, C.Siva Kalyani, Perala Balamurali Krishna, N.Lakshmi, P.Anusha and Sulakshana Sony Cheemala. 2016. A Report of Three Cases of Diphtheria in a Tertiary Care Hospital. Int.J.Curr.Microbiol.App.Sci. 5(4): 675-680. doi: http://dx.doi.org/10.20546/ijcmas.2016.504.077 